\title{
Administration of Vitamin D Metabolites Affects RNA Expression of Xenobiotic Metabolising Enzymes and Function of ABC Transporters in Rats
}

\author{
Karoline Klumpp, ${ }^{1}$ Frauke Lange, ${ }^{1}$ Alexandra S. Muscher-Banse, ${ }^{1}$ Nadine Schnepel, ${ }^{1}$ \\ Kathrin Hansen, ${ }^{1}$ Adrian L. Lifschitz, ${ }^{2}$ Laura Mate, ${ }^{2}$ and Mirja R. Wilkens $\mathbb{D}^{1}$ \\ ${ }^{1}$ Institute of Physiology and Cell Biology, University of Veterinary Medicine Hannover, Hanover, Germany \\ ${ }^{2}$ Laboratory of Veterinary Pharmacology, Faculty of Veterinary Sciences, National University of Central Buenos Aires Province, \\ B7000 Tandil, Argentina
}

Correspondence should be addressed to Mirja R. Wilkens; mirja.wilkens@tiho-hannover.de

Received 6 June 2019; Accepted 13 September 2019; Published 9 October 2019

Guest Editor: Ciriaco Carru

Copyright (c) 2019 Karoline Klumpp et al. This is an open access article distributed under the Creative Commons Attribution License, which permits unrestricted use, distribution, and reproduction in any medium, provided the original work is properly cited.

\begin{abstract}
From studies on different species and in cell culture systems, it has been suggested that vitamin D metabolites might affect the metabolism and elimination of xenobiotics. Although most studies performed on rodents and cell cultures report an upregulation of respective enzymes and transporters, data from the literature are inconsistent. Especially results obtained with sheep differ from these observations. As vitamin D metabolites are widely used as feed additives or therapeutics in livestock animals, we aimed to assess whether these differences indicate species-specific responses or occurred due to the very high dosages used in the rodent studies. Therefore, we applied treatment protocols to rats that had been used previously in sheep or cattle. Forty-eight female rats were divided into three treatment and corresponding placebo groups: (1) a single intraperitoneal injection of $1,25-(\mathrm{OH})_{2} \mathrm{D}_{3}$ or placebo $12 \mathrm{~h}$ before sacrifice; (2) daily supplementation with $25-\mathrm{OHD}_{3}$ by oral gavage or placebo for 10 days; and (3) a single intramuscular injection of vitamin $\mathrm{D}_{3} 10$ days before sacrifice. In contrast to a previous study using sheep, treatment of rats with 1,25-dihydroxyvitamin $\mathrm{D}_{3}$ did not result in an upregulation of cytochrome P450 3A isoenzymes (CYP3A), but a decrease was found in hepatic and intestinal expressions. In addition, a downregulation of P-glycoprotein (P-gp) and breast cancer resistance protein was found in the brain. Taken together, the stimulating effects of vitamin D metabolites on the expression of genes involved in the metabolism and elimination of xenobiotics reported previously for rodents and sheep could not be reproduced. In contrast, we even observed a negative impact on the expression of CYP3A enzymes and their most important regulator, the pregnane X receptor. Most interestingly, we could demonstrate an effect of treatment with 25 -hydroxyvitamin $\mathrm{D}_{3}$ and vitamin $\mathrm{D}_{3}$ on the functional activity of ileal P-glycoprotein (P-gp) using the Ussing chamber technique.
\end{abstract}

\section{Introduction}

Due to public interest on the potential beneficial effects not only on calcium homeostasis and bone metabolism but also on the possible prevention of diabetes, cancer, inflammatory bowel diseases, etc., vitamin $\mathrm{D}$ supplementation has become a common practice in many countries in recent years $[1,2]$. However, as many products are sold over the counter, the dosages are often not critically determined by medical professionals. In livestock including high yielding dairy cows, high doses of vitamin $\mathrm{D}$ are used as a feed additive and for treatment of imbalances of mineral homeostasis [3-5].

Many xenobiotica are substrates of cytochrome P450 (CYP) 3A4, an enzyme that is involved in the phase I metabolism of approximately $50 \%$ of all therapeutics used in humans [6]. Absorption and excretion rates of a broad range of endogenous and exogenous hydrophobic molecules are substantially determined by the efflux transporter P-glycoprotein (P-gp). As several compounds can inhibit or induce its activity, P-gp plays a crucial role in numerous drug-drug 
interactions [7]. It was shown that vitamin D metabolites can be substrates of both CYP3A4 and P-gp [8,9].

Interestingly, oral supplementation with vitamin $\mathrm{D}$ and UV exposure affecting endogenous synthesis of vitamin D has been reported to be associated with changes in plasma concentrations of certain therapeutics. In humans, dosagedependent plasma concentrations of tacrolimus and sirolimus were found to be decreased in summer [10]. Both immunosuppressants are substrates of CYP 3A4 [6] and eliminated by P-gp [11]. In addition, it could be demonstrated that patients medicated with atorvastatin, a drug that is also metabolized by CYP3A4, showed lower plasma concentrations when the treatment was combined with oral vitamin D supplementation [12]. In contrast, such an interaction could not be detected in a study on intestinal absorption of the P-gp substrate digoxin [13], and the results of studies investigating these potential drug-drug interactions in cell culture systems and rodents are inconsistent too.

Human intestinal cells (Caco-2 and LS180) only express the CYP3A4 isoenzyme if 1,25-dihydroxyvitamin $\mathrm{D}_{3}(1,25$ $\left.(\mathrm{OH})_{2} \mathrm{D}_{3}\right)$ is added to the medium, probably mediated via the vitamin $\mathrm{D}$ receptor (VDR). Likewise, primary human hepatocytes respond in the same way to such a treatment although this is not found in all hepatic cell lines. It has been suggested that VDR might bind to xenobiotic-responsive elements in certain CYP promoters [14-16]. An upregulation of P-gp induced by hydroxylated vitamin $\mathrm{D}$ metabolites as well as an increased functional activity could also be found in Caco-2 cells [17].

In rats, the isoforms CYP3A1/23, CYP3A2, CYP3A9, CYP3A18, and CYP3A62 are expressed with CYP3A9 and CYP3A62 being the most important isoforms in the intestine [18-20]. Administration of $1,25-(\mathrm{OH})_{2} \mathrm{D}_{3}$ and the vitamin $\mathrm{D}$ analog 19nor-1,25- $(\mathrm{OH})_{2} \mathrm{D}_{3}$ resulted in a transient increase in intestinal RNA expression of CYP3A9 [21]. In contrast, repeated administration had no effect on CYP3A9 intestinal RNA expression, but the expression of CYP3A1/23 and CYP3A proteins was increased $[22,23]$ as well as renal RNA expression of CYP3A9 [24]. In sheep, the administration of $1,25-(\mathrm{OH})_{2} \mathrm{D}_{3}$ led to a pronounced stimulation of both renal and intestinal CYP3A24 [25], the ovine gene orthologous to human CYP3A4 [26]. Expression and activity of intestinal $\mathrm{P}$-gp were not altered in $1,25-(\mathrm{OH})_{2} \mathrm{D}_{3}$-treated rats [27], while in sheep, hepatic and intestinal expressions were even slightly decreased after oral supplementation with 25hydroxyvitamin $\mathrm{D}\left(25-\mathrm{OHD}_{3}\right)$ [25]. Results on hepatic P-gp expression in rats were inconsistent with different dosages [22], whereas in the kidney and brain of mice, expression and activity of P-gp were stimulated [28].

To investigate whether the observed discrepancies are species differences or are the result of the very high dosages used repeatedly in rodents, we applied treatment protocols to rats that had been used before in sheep or cattle: $0.5 \mu \mathrm{g}$ $1,25-(\mathrm{OH})_{2} \mathrm{D}_{3}$ per $\mathrm{kg}$ body weight (BW) intravenously 12 hours before sacrifice, $6 \mu \mathrm{g} 25$-hydroxyvitamin $\mathrm{D}_{3}(25-$ $\mathrm{OHD}_{3}$ ) per $\mathrm{kg} \mathrm{BW}$ per os daily for 10 days, and $300 \mu \mathrm{g}$ vitamin $\mathrm{D}_{3}$ per kg BW intramuscularly once 10 days before sacrifice. After sampling, we investigated RNA expression of genes involved in calcium absorption and vitamin $\mathrm{D}$ metabolism: VDR, pregnane X receptor (PXR), different CYP3A enzymes, P-gp, and breast cancer resistance protein (BCRP) as well as the functional activity of ileal P-gp.

\section{Materials and Methods}

2.1. Animals, Treatments, and Sampling. The protocols of the animal treatment were approved by the Lower Saxony State Office for Consumer Protection and Food Safety (33.1242502-04-15/1995) and their conduct supervised by the Animal Welfare Commissioner of the University of Veterinary Medicine Hannover in accordance with the German Animal Welfare Law.

In the current study, 48 female Sprague Dawley rats aged 8 to 11 weeks (body weight 10 days before sacrifice: $220 \pm 7.0 \mathrm{~g}$ ) were kept on a standard chow (ssniff Spezialdiäten GmbH, Soest, Germany) fed ad libitum and maintained under a 12 : 12-hour light and dark cycle. The animals were divided into three treatment and corresponding placebo groups: (1) a single intraperitoneal injection of $1,25-(\mathrm{OH})_{2} \mathrm{D}_{3} \quad(N=9$, $0.5 \mu \mathrm{g} / \mathrm{kg}$ body weight, Decostriol ${ }^{\circledR}$, mibe GmbH Arzneimittel, Brehna, Germany) or placebo $(N=7) 12 \mathrm{~h}$ before sacrifice; (2) daily supplementation with $25-\mathrm{OHD}_{3}$ by oral gavage $\left(N=8,6 \mu \mathrm{g} / \mathrm{kg}\right.$ body weight, Dedrogyl ${ }^{\circledR}$, Desma $\mathrm{GmbH}$, Mainz-Kastel, Germany, diluted with tap water to a total volume of $1 \mathrm{ml})$ or placebo $(N=8,1 \mathrm{ml}$ of tap water with addition of propylene glycole, the nonpharmacological compound of Dedrogyl ${ }^{\circledR}$ ) for 10 days; and (3) a single intramuscular injection of vitamin $\mathrm{D}_{3}(N=8,300 \mu \mathrm{g} / \mathrm{kg}$ body weight, $\mathrm{D}_{3}$-Vicotrat ${ }^{\circledR}$, Heyl Chemisch-pharmazeutische Fabrik GmbH \& Co. KG, Berlin, Germany) or placebo $(N=8) 10$ days before sacrifice.

The animals were anesthetized by exposure to carbon dioxide and sacrificed immediately by exsanguination via cardiac puncture. Serum samples were prepared and stored at $-20^{\circ} \mathrm{C}$. Tissues for the isolation of RNA were collected within $10 \mathrm{~min}$ postmortem and rinsed with ice-cold saline (0.9\%). The small intestinal epithelia (proximal jejunum and distal jejunum/ileum, the latter one refers to the segment directly proximal from that used for the Ussing chamber experiments) was scraped from the underlying submucosal and muscle layers with a glass slide. The tissues were frozen in liquid nitrogen and stored at $-80^{\circ} \mathrm{C}$ until analysis. For the Ussing chamber experiments, the ileum was opened along the mesenteric line, rinsed with ice-cold $0.9 \%(\mathrm{w} / \mathrm{v})$ saline, and kept in ice-cold buffer solution $(113.6 \mathrm{mM} \mathrm{NaCl}$, $5.4 \mathrm{mM} \mathrm{KCl}, 1.2 \mathrm{mM} \mathrm{CaCl}_{2}, 1.2 \mathrm{mM} \mathrm{MgCl}, 0.2 \mathrm{mM} \mathrm{HCl}$, $0.6 \mathrm{mM} \mathrm{NaH}_{2} \mathrm{PO}_{4}, 2.4 \mathrm{mM} \mathrm{Na}_{2} \mathrm{HPO}_{4}, 21.0 \mathrm{mM} \mathrm{NaHCO}$, $10 \mathrm{mM}$ glucose, and $19.8 \mathrm{mM}$ mannitol) aerated with carbogen. Serosal and muscle layers were peeled off carefully using forceps, and the epithelia were mounted in the chambers within $30 \mathrm{~min}$ after sacrifice.

2.2. Plasma Analyses. Serum was analyzed for total calcium colorimetrically by the o-cresolphthalein complexone method [29]. Intra- and interassay coefficients in our laboratory are $5.09 \%$ and $6.88 \%$. A commercial ELISA 
(25(OH)-Vitamin D direct day ELISA ${ }^{\circledR}$, Immundiagnostik AG, Bensheim, Germany) was used to determine serum 25OHD concentrations. Intra- and interassay coefficients in our laboratory and sensitivities are $10.1 \%, 13.4 \%$, and $6.08 \mathrm{ng} / \mathrm{ml}$. According to the manufacturer, cross-reactivity with other vitamin $\mathrm{D}$ metabolites compared to $25-\mathrm{OHD}_{3}$ is $67.8 \%$ for $25-\mathrm{OHD}_{2}$ and $100 \%$ for $24,25-(\mathrm{OH})_{2} \mathrm{D}_{3}$.

Measurement of serum concentrations of $1,25-(\mathrm{OH})_{2} \mathrm{D}$ was carried out by a commercial diagnostic laboratory using a competitive ELISA following solvent extraction (1,25$(\mathrm{OH})_{2}$-Vitamin D ELISA ${ }^{\circledR}$, Immundiagnostik AG, Bensheim, Germany). Intra- and interassay coefficients and sensitivities documented and provided by the laboratory are $6.69 \%, 9.00 \%$, and $4.80 \mathrm{pg} / \mathrm{ml}$. Cross-reactivity with 1,25 $(\mathrm{OH})_{2} \mathrm{D}_{2}$ compared to $1,25-(\mathrm{OH})_{2} \mathrm{D}_{3}$ is declared to be $41 \%$.

2.3. Quantification of RNA Expression. Total RNA was isolated using the RNeasy plus Mini Kit (Qiagen, Hilden, Germany) with genomic DNA eliminator spin columns in accordance with the manufacturer's protocol. Concentration and quality of the RNA were determined by UV absorbance, and $200 \mathrm{ng}$ was reverse transcribed using random hexamer primers and TaqMan-reverse-transcription reagents (Applied Biosystems, Darmstadt, Germany).

RNA expression of $\beta$-actin, TRPV6 (transient receptor potential vanilloid type 6), $\mathrm{CaBP}-\mathrm{D}_{9 \mathrm{~K}}$ (calbindin- $\mathrm{D}_{9 \mathrm{~K}}$ ), PMCA1b (plasma membrane calcium ATPase 1b), CYP27B1 (cytochrome P450 27B1, $1 \alpha$-hydroxylase), CYP24A1 (24-hydroxylase), VDR (vitamin D receptor) and PXR (pregnane X receptor), CYP3A9, CYP3A18, CYP3A62, MDR1a, and MDR1b (ABCB1, P-gp, P-glycoprotein), and BCRP (ABCG2, breast cancer resistance protein) was determined using SYBR Green ${ }^{\circledR}$ PCR assays. Specific primers (Table 1) were purchased from Life Technologies (Darmstadt, Germany). Reaction mixtures $(20 \mu \mathrm{l})$ contained KAPA SYBR FAST Universal Master Mix (PEQLAB Biotechnologie $\mathrm{GmbH}$, Erlangen, Germany), specific primers (200 nM), and $16 \mathrm{ng}$ reverse transcribed RNA. PCR products were amplified $\left(95^{\circ} \mathrm{C}, 3 \mathrm{~min} ; 40\right.$ cycles of $95^{\circ} \mathrm{C}, 10 \mathrm{~s}$; and $\left.60^{\circ} \mathrm{C}, 30 \mathrm{~s}\right)$ and detected on a real-time PCR cycler (CFX96TM, BioRad, Munich, Germany). The thermal profile for melt curve determination began with an incubation of $10 \mathrm{~min}$ at $55^{\circ} \mathrm{C}$ with a gradual increase in temperature $\left(0.5^{\circ} \mathrm{C} / 10 \mathrm{~s}\right)$ to $95^{\circ} \mathrm{C}$.

Expression of GAPDH (glyceraldehyde 3-phosphate dehydrogenase) was determined using gene-specific TaqMan ${ }^{\circledR}$ primers and probes (TIB Molbiol GmbH, Berlin, Germany). Reaction mixtures $(20 \mu \mathrm{l})$ contained TaqMan ${ }^{\circledR}$ Universal PCR Master Mix (Thermo Fisher, Darmstadt, Germany), $50 \mathrm{pM}$ specific primers, $25 \mathrm{pM}$ specific probe, and $16 \mathrm{ng}$ reverse-transcribed RNA. PCR products were amplified as follows: $50^{\circ} \mathrm{C}, 2 \mathrm{~min} ; 95^{\circ} \mathrm{C}, 10 \mathrm{~min} ; 40$ cycles of $95^{\circ} \mathrm{C}, 15 \mathrm{~s}$; and $60^{\circ} \mathrm{C}, 1 \mathrm{~min}$.

Absolute copy numbers were determined using calibration curves generated with cloned PCR fragment standards as described elsewhere [31]. Efficiency of the PCR assays tested in advance for dilutions of cDNA and cloned standard ranged from 85 to $105 \%$. Specificity of the amplicons was verified using NCBI Blast (http://blast.ncbi.nlm.nih.gov/Blast.cgi).
Parallel PCR assays for each gene target were performed with cDNA samples, genomic standards, and a no-template control with water. Expression of target genes was normalized using the expression of GAPDH or $\beta$-actin as stable expressed reference genes during treatments. Each series of experiments was carried out twice.

2.4. Using Chamber Experiments. For each ileum, six pieces of tissue were mounted between the two halves of incubation chambers with an exposed area of $0.50 \mathrm{~cm}^{2}$. Thereby, the Ussing chambers were separated in a serosal and a mucosal compartment each connected to circulation reservoirs filled with respective buffer solutions $(113.6 \mathrm{mM} \mathrm{NaCl}, 5.4 \mathrm{mM}$ $\mathrm{KCl}, 1.2 \mathrm{mM} \mathrm{CaCl}_{2}, 1.2 \mathrm{mM} \mathrm{MgCl}, 0.2 \mathrm{mM} \mathrm{HCl}, 0.6 \mathrm{mM}$ $\mathrm{NaH}_{2} \mathrm{PO}_{4}, 2.4 \mathrm{mM} \mathrm{Na} \mathrm{HPO}_{4}, 21.0 \mathrm{mM} \mathrm{NaHCO} 3,10 \mathrm{mM}$ glucose, and $19.8 \mathrm{mM}$ mannitol) which were maintained at $38^{\circ} \mathrm{C}$ by water jackets and continuously stirred and aerated with carbogen by a gas lift system. A computer-controlled voltage clamp device (Mussler Scientific Instruments, Aachen, Germany) was used to determine tissue conductance $\left(G_{t}\right)$ and transepithelial potential difference $\left(\mathrm{PD}_{\mathrm{t}}\right)$ with reference to the mucosal side. All experiments were carried out under open-circuit current conditions.

Activity of P-gp was determined by the use of rhodamine-123 (Sigma-Aldrich Chemie GmbH, Schnelldorf, Germany) that was added to a final concentration of $26 \mu \mathrm{M}$ either to the serosal (four chambers per animal) or to the mucosal side of the tissue (two chambers per animal). Two of the four chambers with the serosal side as donor compartment were additionally provided with $100 \mu \mathrm{M}$ verapamil (Sigma-Aldrich Chemie GmbH, Schnelldorf, Germany) to inhibit P-gp-mediated transport of rhodamine-123. After an equilibration period of $30 \mathrm{~min}$, six samples of $400 \mu$ l each were taken at intervals of $30 \mathrm{~min}$ and this volume was immediately replaced by $400 \mu \mathrm{l}$ of the respective buffer solution. The concentration of rhodamine-123 in the acceptor compartment was measured at $485 \mathrm{~nm}$ (extinction) and $520 \mathrm{~nm}$ (emission), calculated by interpolation from a standard curve and corrected cumulatively for the previously removed samples (Infinite M200, Tecan GmbH, Crailsheim, Germany). The secretory response of the intestinal segments to forskolin $(10 \mu \mathrm{M}$, added to the serosal side, Sigma-Aldrich Chemie GmbH, Schnelldorf, Germany) represented by the increase in $\mathrm{PD}_{\mathrm{t}}$ served as a parameter to survey the viability of the epithelium at the end of the experiments.

2.5. Statistical Analyses and Presentation of Data. As all approaches included a placebo treatment administered through the same route, results on RNA expression were compared by Student's $t$ test for unpaired observations for each treatment versus the respective control $\left(P<0.05^{*}\right.$; $\left.P<0.01^{* *} ; P<0.001^{* * *}\right)$. Data are presented in relation to the corresponding control group. A second-order polynomial model could be calculated for rhodamine-123 net increase over time. In addition, results were compared by 2 way ANOVA for repeated measures (time, treatment, and interaction) followed by Bonferroni's posttest. All statistical 
TAble 1: Primers used for quantitative RT-PCR assays.

\begin{tabular}{|c|c|c|}
\hline Gene and source & Sequence & Product size \\
\hline & for $5^{\prime}$-TTGTCAGCAATGCATCCTGC-3' & \\
\hline GAPDH & rev $5^{\prime}$-CGGCATGTCAGATCCACAAC- $3^{\prime}$ & 307 \\
\hline NM_017008.4 & Probe: $5^{\prime}$-6FAM-TGGCCCCTCTGGAAAGCTGTGGCG-BBQ & \\
\hline$\beta$-actin & for $5^{\prime}$-AAGTCCCTCACCCTCCCAAAAG-3' & \\
\hline [30] & rev $5^{\prime}$-AAGCAATGCTGTCACCTTCCC-3' & 97 \\
\hline$B R C P$ & for 5'-AGTCCGGAAAACAGCTGAGA-3' & \\
\hline XM_006236573.3 & rev 5'-CAAGATGACGTTGTGATGGG-3' & 235 \\
\hline$C a B P-D_{9 K}$ & for $5^{\prime}$-TGAGCGCTAAGAAATCTCCCG-3' & \\
\hline NM_012521.2 & rev 5'-GCTGGGGAACTCTGACTGAAT-3' & 125 \\
\hline СYPЗА9 & for $5^{\prime}$-CCTGGCTGCTCCTGGTTATC-3' & \\
\hline NM_147206.2 & rev 5'-AAAGGTTTGGGCCCAGGAAT-3' & 100 \\
\hline CYP3А 18 & for $5^{\prime}$-CTACGGTGATGGCATGTGGA-3' & \\
\hline NM_145782.1 & rev $5^{\prime}$-CATTGGCCCAAAACACCGAC- $3^{\prime}$ & 178 \\
\hline CYP3A62 & for $5^{\prime}$-TCTTGCATACCGCCATGGAT-3' & \\
\hline NM_001024232.1 & rev $5^{\prime}$-AAAGCTCCGACGGTTTGTGA-3' & 175 \\
\hline CYP24A1 & for $5^{\prime}$-CTCGGACCCTTGACAAACCA-3' & \\
\hline NM_201635.2 & rev $5^{\prime}$-CCGAATGGGAGATGAGCGAA-3' & 184 \\
\hline CYP27B1 & for $5^{\prime}$-TACCCCTGCTAAAGGCTGTGA-3' & \\
\hline NM_053763.1 & rev 5'-GAGTTGGGTTCCCGAAACTGG-3' & 181 \\
\hline$M D \bar{R} 1 a$ & for $5^{\prime}$-TCTGGCGGCCATTATCCAT-3' & \\
\hline NM_133401.1 & rev $5^{\prime}$-TCATACTACGGTTGTTTCCTACATTTG-3' & 101 \\
\hline$M D \bar{R} 1 b$ & for $5^{\prime}$-TGAATCCCAAAGTGACACTGGT-3' & \\
\hline NM_012623.2 & rev $5^{\prime}$-ATACTTCTGCGAATTGATCTCCTTATT-3' & 87 \\
\hline$P M C A 1 b$ & for $5^{\prime}$-AATGCTTTCCAGAGTGGAGGT-3' & \\
\hline NM_053311.1 & rev $5^{\prime}$-TCGGATACCCCACAGGAGT-3' & 148 \\
\hline PXR & for $5^{\prime}$-GCGTCATCAACTTCGCCAAA-3' & \\
\hline NM_052980.2 & rev $5^{\prime}$-TTCTGGAAGCCGCCATTAGG-3' & 193 \\
\hline TRPV6 & for $5^{\prime}$-GAGCACAGGTTGTGGCTACT-3' & \\
\hline NM_053686.1 & rev $5^{\prime}$-TCCACCCTCAAGAACCAGCG-3' & 122 \\
\hline$V D R$ & for $5^{\prime}$-ACAGTCTGAGGCCCAAGCTA-3' & \\
\hline [24] & rev $5^{\prime}$-TCCCTGAAGTCAGCGTAGGT-3' & 103 \\
\hline
\end{tabular}

analyses including the linear regression analyses were done using GraphPad Prism Version 6.00 (GraphPad Software, San Diego, California, USA).

\section{Results}

3.1. Body Weight and Serum Parameters. All animals were clinically healthy during the study. Body weight and serum parameters at sacrifice are presented in Table 2. Body weight was not affected. Treatment with $1,25-(\mathrm{OH})_{2} \mathrm{D}_{3}$ resulted in significantly greater serum concentrations of $1,25-(\mathrm{OH})_{2} \mathrm{D}_{3}$ $(P<0.001)$ and total calcium $(P<0.001)$, while administration of $25-\mathrm{OHD}_{3}$ and vitamin $\mathrm{D}_{3}$ only increased serum concentrations of $25-\mathrm{OHD}_{3}(P<0.001 ; P<0.001)$.

3.2. RNA Expression. RNA expression of genes involved in vitamin $\mathrm{D}$ metabolism, transepithelial calcium transport, metabolism, and elimination of xenobiotics as well as nuclear receptors is given in Tables 3-7.

Only intraperitoneal administration of $1,25-(\mathrm{OH})_{2} \mathrm{D}_{3}$ resulted in a significant downregulation of the renal CYP27B1 $(P<0.001$, Table 5), while the renal CYP24A1 $(P<0.001$, Table 5), renal VDR $(P<0.05$, Table 5$)$, and the intestinal calcium transport protein $\mathrm{CaBPD}_{9 \mathrm{~K}}$ were significantly upregulated $(P<0.001$, Table 3$)$. In addition, the treatment increased the RNA expression of PXR in the brain by trend $(P=0.053$, Table 7$)$ and decreased the RNA expression of hepatic PXR $(P<0.05$, Table 6$)$ and CYP3A18 $(P<0.05$, Table 6$)$, renal PXR $(P<0.05$, Table 5$)$, and intestinal CYP3A9 $(P<0.05$, Table 4$)$. RNA expression of both efflux transporters investigated, MDRla and BCRP, and was significantly decreased in the brain $(P<0.01 ; P<0.05$, Table 7$)$.

While intramuscular treatment with vitamin $\mathrm{D}_{3}$ only exerted a decreasing effect on renal PXR $(P<0.05$, Table 5), oral supplementation with $25-\mathrm{OHD}_{3}$ did not affect any of the genes investigated.

Regression analyses revealed linear correlations between the expression of PXR and CYP3A18 $(y=2.220 \pm 0.391$ $\left.x-0.022 \pm 0.011, \quad r^{2}: \quad 0.47, \quad P<0.001\right)$ and MDR1a $\left(y=1.290 \pm 0.121 x-0.007 \pm 0.003, r^{2}: 0.75, P<0.001\right)$ in the proximal jejunum in all groups except for rats treated with $0.5 \mu \mathrm{g} / \mathrm{kg}$ body weight $12 \mathrm{~h}$ before sacrifice (Figure 1 ).

3.3. Ileal P-gp Activity. While no effect was found in animals treated with $1,25-(\mathrm{OH})_{2} \mathrm{D}_{3} 12$ hours before sacrifice (data not shown), rats treated with $25-\mathrm{OHD}_{3}$ or vitamin $\mathrm{D}_{3}$ showed a more pronounced inhibition of probably $\mathrm{P}$-gpmediated secretion of rhodamine-123 after addition of verapamil to the mucosal compartment of the Ussing chamber $(P<0.001)$. Analysis of rhodamine-123 net increase 
TABLE 2: Body weight and serum parameters of rats treated with different vitamin D metabolites.

\begin{tabular}{lccc}
\hline & $\begin{array}{c}1,25-(\mathrm{OH})_{2} \mathrm{D}_{3} \\
(0.5 \mu \mathrm{g} / \mathrm{kg} \text { body weight, administered } \\
\text { intraperitoneally once, } 12 \mathrm{~h} \text { before } \\
\text { sacrifice })\end{array}$ & $\begin{array}{c}25-\mathrm{OHD}_{3} \\
(6 \mu \mathrm{g} / \mathrm{kg} \text { body weight, administered } \\
\text { daily by oral gavage for 10 days })\end{array}$ & $\begin{array}{c}\text { Vitamin } \mathrm{D}_{3} \\
\text { intramuscularly, once } 10 \text { days before } \\
\text { sacrifice })\end{array}$ \\
\hline Body weight $(\mathrm{g})$ & $254 \pm 7.74$ & $263 \pm 4.62$ & $246 \pm 6.10$ \\
$25-\mathrm{OHD} \mathrm{H}_{3}$ & $(241 \pm 6.17)$ & $(258 \pm 10.2)$ & $(247 \pm 7.30)$ \\
$(\mathrm{ng} / \mathrm{ml})$ & $32.0 \pm 4.02$ & $87.9 \pm 12.0^{* * *}$ & $(25.6 \pm 1.80)$ \\
$1,25-(\mathrm{OH})_{2} \mathrm{D}_{3}$ & $(23.1 \pm 3.88)$ & $27.0 \pm 3.32$ & $(31.5 \pm 4.73)$ \\
$(\mathrm{pg} / \mathrm{ml})$ & $237.6 \pm 21.2^{* * *}$ & $(39.3 \pm 7.37)$ & $27.1 \pm 1.78$ \\
Total calcium & $(37.4 \pm 7.61)$ & $2.71 \pm 0.02$ & $(30.9 \pm 3.51)$ \\
$(\mathrm{mM})$ & $2.85 \pm 0.03^{* * *}$ & $(2.70 \pm 0.03)$ & $2.64 \pm 0.03$ \\
\hline
\end{tabular}

Mean \pm SEM of respective control groups are given in brackets; asterisks indicate significant differences between treatment and control groups; ${ }^{* * *} P<0.001$, ${ }^{* *} P<0.01$.

TABle 3: RNA expression in the proximal jejunum of rats treated with different vitamin D metabolites normalized to GAPDH.

\begin{tabular}{|c|c|c|c|}
\hline & $\begin{array}{c}1,25-(\mathrm{OH})_{2} \mathrm{D}_{3} \\
(0.5 \mu \mathrm{g} / \mathrm{kg} \text { body weight, administered } \\
\text { intraperitoneally once, } 12 \mathrm{~h} \text { before } \\
\text { sacrifice })\end{array}$ & $\begin{array}{c}25-\mathrm{OHD}_{3} \\
(6 \mu \mathrm{g} / \mathrm{kg} \text { body weight, administered daily } \\
\text { by oral gavage for } 10 \text { days })\end{array}$ & $\begin{array}{c}\text { Vitamin } \mathrm{D}_{3} \\
\text { (300 } \mu \mathrm{g} / \mathrm{kg} \text { body weight, administered } \\
\text { intramuscularly, once } 10 \text { days before } \\
\text { sacrifice) }\end{array}$ \\
\hline TRPV6 & $\begin{array}{c}0.879 \pm 0.142 \\
(1 \pm 0.08)\end{array}$ & $\begin{array}{c}1.187 \pm 0.267 \\
(1 \pm 0.148)\end{array}$ & $\begin{array}{l}1.741 \pm 0.938 \\
(1 \pm 0.161)\end{array}$ \\
\hline$C a B P-D_{9 K}$ & $\begin{array}{l}4.773 \pm 0.418^{* * *} \\
\quad(1 \pm 0.231)\end{array}$ & $\begin{array}{c}0.469 \pm 0.185 \\
(1 \pm 0.342)\end{array}$ & $\begin{array}{c}0.437 \pm 0.076 \\
(1 \pm 0.480)\end{array}$ \\
\hline$P M C A 1 b$ & $\begin{array}{c}0.790 \pm 0.082 \\
(1 \pm 0.0731)^{\prime}\end{array}$ & $\begin{array}{c}1.054 \pm 0.156 \\
(1 \pm 0.061)\end{array}$ & $\begin{array}{c}1.019 \pm 0.286 \\
(1 \pm 0.283)\end{array}$ \\
\hline$V D R$ & $\begin{array}{c}1.118 \pm 0.107 \\
(1 \pm 0.254)\end{array}$ & $\begin{array}{c}1.489 \pm 0.362 \\
(1 \pm 0.148)\end{array}$ & $\begin{array}{c}2.630 \pm 1.682 \\
(1 \pm 0.113)\end{array}$ \\
\hline$P X R$ & $\begin{array}{c}1.350 \pm 0.165 \\
(1 \pm 0.150)\end{array}$ & $\begin{array}{c}1.430 \pm 0.271 \\
(1 \pm 0.122)\end{array}$ & $\begin{array}{l}0.958 \pm 0.087 \\
(1 \pm 0.080)\end{array}$ \\
\hline СҮРЗА9 & $\begin{array}{c}0.756 \pm 0.130 \\
(1 \pm 0.148)\end{array}$ & $\begin{array}{c}1.219 \pm 0.125 \\
(1 \pm 0.207)\end{array}$ & $\begin{array}{c}1.056 \pm 0.219 \\
(1 \pm 0.162)\end{array}$ \\
\hline СYР $3 A 18$ & $\begin{array}{c}0.936 \pm 0.108 \\
(1 \pm 0.169)\end{array}$ & $\begin{array}{c}1.339 \pm 0.162 \\
(1 \pm 0.091)\end{array}$ & $\begin{array}{l}1.226 \pm 0.203 \\
(1 \pm 0.095)\end{array}$ \\
\hline CYР3A62 & $\begin{array}{c}0.907 \pm 0.130 \\
(1 \pm 0.123)\end{array}$ & $\begin{array}{c}1.163 \pm 0.139 \\
(1 \pm 0.120)\end{array}$ & $\begin{array}{c}1.049 \pm 0.198 \\
(1 \pm 0.144)\end{array}$ \\
\hline$M D R 1 a$ & $\begin{array}{c}1.154 \pm 0.150 \\
(1 \pm 0.252)\end{array}$ & $\begin{array}{c}1.723 \pm 0.393 \\
(1 \pm 0.151)\end{array}$ & $\begin{array}{c}1.174 \pm 0.168 \\
(1 \pm 0.193)\end{array}$ \\
\hline
\end{tabular}

Means \pm SEM of respective control groups set to 1 are given in brackets; asterisks indicate significant differences between treatment and control groups; ${ }^{* * *} P<0.001$.

TABLE 4: RNA expression in the distal jejunum/ileum of rats treated with different vitamin D metabolites normalized to GAPDH.

\begin{tabular}{|c|c|c|c|}
\hline & $\begin{array}{c}1,25-(\mathrm{OH})_{2} \mathrm{D}_{3} \\
(0.5 \mu \mathrm{g} / \mathrm{kg} \text { body weight, administered } \\
\text { intraperitoneally once, } 12 \mathrm{~h} \text { before } \\
\text { sacrifice })\end{array}$ & $\begin{array}{l}25-\mathrm{OHD}_{3} \\
(6 \mu \mathrm{g} / \mathrm{kg} \text { body weight, administered daily } \\
\text { by oral gavage for } 10 \text { days })\end{array}$ & $\begin{array}{c}\text { Vitamin } \mathrm{D}_{3} \\
(300 \mu \mathrm{g} / \mathrm{kg} \text { body weight, administered } \\
\text { intramuscularly, once } 10 \text { days before } \\
\text { sacrifice })\end{array}$ \\
\hline$V D R$ & $\begin{array}{c}0.976 \pm 0.061 \\
(1 \pm 0.073)\end{array}$ & $\begin{array}{l}0.732 \pm 0.060 \\
(1 \pm 0.350)\end{array}$ & $\begin{array}{c}1.027 \pm 0.068 \\
(1 \pm 0.089)\end{array}$ \\
\hline$P X R$ & $\begin{array}{l}0.991 \pm 0.083 \\
(1 \pm 0.128)\end{array}$ & $\begin{array}{l}1.163 \pm 0.083 \\
(1 \pm 0.131)\end{array}$ & $\begin{array}{l}1.178 \pm 0.105 \\
(1 \pm 0.086)\end{array}$ \\
\hline СУРЗАЯ & $\begin{array}{l}0.607 \pm 0.088^{* *} \\
\quad(1 \pm 0.055)\end{array}$ & $\begin{array}{l}1.546 \pm 0.222 \\
(1 \pm 0.185)\end{array}$ & $\begin{array}{l}1.096 \pm 0.162 \\
(1 \pm 0.170)\end{array}$ \\
\hline СYР $3 A 18$ & $\begin{array}{l}0.763 \pm 0.126 \\
(1 \pm 0.082)\end{array}$ & $\begin{array}{l}1.061 \pm 0.113 \\
(1 \pm 0.160)\end{array}$ & $\begin{array}{l}1.381 \pm 0.239 \\
(1 \pm 0.170)\end{array}$ \\
\hline СYРЗА62 & $\begin{array}{l}0.775 \pm 0.082 \\
(1 \pm 0.064)\end{array}$ & $\begin{array}{l}1.302 \pm 0.105 \\
(1 \pm 0.146)\end{array}$ & $\begin{array}{l}0.838 \pm 0.074 \\
(1 \pm 0.138)\end{array}$ \\
\hline MDR1a & $\begin{array}{c}1.089 \pm 0.071 \\
(1 \pm 0.074)\end{array}$ & $\begin{array}{c}1.299 \pm 0.191 \\
(1 \pm 0.159)\end{array}$ & $\begin{array}{c}1.058 \pm 0.160 \\
(1 \pm 0.242)\end{array}$ \\
\hline
\end{tabular}

Mean \pm SEM of respective control groups set to 1 are given in brackets; asterisks indicate significant differences between treatment and control groups; ${ }^{* *} P<0.01$. 
TABLE 5: RNA expression in the kidney of rats treated with different vitamin D metabolites normalized to GAPDH.

\begin{tabular}{|c|c|c|c|}
\hline & $\begin{array}{c}1,25-(\mathrm{OH})_{2} \mathrm{D}_{3} \\
(0.5 \mu \mathrm{g} / \mathrm{kg} \text { body weight, administered } \\
\text { intraperitoneally once, } 12 \mathrm{~h} \text { before } \\
\text { sacrifice })\end{array}$ & $\begin{array}{c}25-\mathrm{OHD}_{3} \\
(6 \mu \mathrm{g} / \mathrm{kg} \text { body weight, administered daily } \\
\text { by oral gavage for } 10 \text { days })\end{array}$ & $\begin{array}{c}\text { Vitamin } \mathrm{D}_{3} \\
(300 \mu \mathrm{g} / \mathrm{kg} \text { body weight, administered } \\
\text { intramuscularly, once } 10 \text { days before } \\
\text { sacrifice) }\end{array}$ \\
\hline$V D R$ & $\begin{array}{c}1.488 \pm 0.135^{*} \\
(1 \pm 0.066)\end{array}$ & $\begin{array}{l}0.833 \pm 0.076 \\
(1 \pm 0.072)\end{array}$ & $\begin{array}{c}0.775 \pm 0.075 \\
(1 \pm 0.089)\end{array}$ \\
\hline$P X R$ & $\begin{array}{c}0.804 \pm 0.063^{*} \\
(1 \pm 0.048)\end{array}$ & $\begin{array}{c}0.905 \pm 0.082 \\
(1 \pm 0.075)\end{array}$ & $\begin{array}{c}0.729 \pm 0.092^{*} \\
\quad(1 \pm 0.068)\end{array}$ \\
\hline CYP24A1 & $\begin{array}{l}32.28 \pm 5.041^{* * *} \\
\quad(1 \pm 0.276)\end{array}$ & $\begin{array}{l}1.292 \pm 0.464 \\
(1 \pm 0.464)\end{array}$ & $\begin{array}{l}1.958 \pm 0.530 \\
(1 \pm 0.202)\end{array}$ \\
\hline CYP27B1 & $\begin{array}{l}0.187 \pm 0.026^{* * *} \\
\quad(1 \pm 0.152)\end{array}$ & $\begin{array}{c}1.034 \pm 0.264 \\
(1 \pm 0.368)\end{array}$ & $\begin{array}{c}0.429 \pm 0.104 \\
(1 \pm 0.558)\end{array}$ \\
\hline MDR1a & $\begin{array}{l}1.240 \pm 0.078 \\
(1 \pm 0.082)\end{array}$ & $\begin{array}{l}1.295 \pm 0.142 \\
(1 \pm 0.147)\end{array}$ & $\begin{array}{l}0.653 \pm 0.065 \\
(1 \pm 0.345)\end{array}$ \\
\hline$M D R 1 b$ & $\begin{array}{c}0.915 \pm 0.147 \\
(1 \pm 0.253) \\
\end{array}$ & $\begin{array}{c}1.227 \pm 0.366 \\
(1 \pm 0.205) \\
\end{array}$ & $\begin{array}{c}1.193 \pm 0.291 \\
(1 \pm 0.157) \\
\end{array}$ \\
\hline
\end{tabular}

Means \pm SEM of respective control groups set to 1 are given in brackets; asterisks indicate significant differences between treatment and control groups; ${ }^{* * *} P<0.001,{ }^{*} P<0.05$.

TABLE 6: RNA expression in the liver of rats treated with different vitamin D metabolites normalized to $\beta$-actin.

\begin{tabular}{|c|c|c|c|}
\hline & $\begin{array}{c}1,25-(\mathrm{OH})_{2} \mathrm{D}_{3} \\
(0.5 \mu \mathrm{g} / \mathrm{kg} \text { body weight, administered } \\
\text { intraperitoneally once, } 12 \mathrm{~h} \text { before } \\
\text { sacrifice })\end{array}$ & $\begin{array}{c}25-\mathrm{OHD}_{3} \\
(6 \mu \mathrm{g} / \mathrm{kg} \text { body weight, administered daily } \\
\text { by oral gavage for } 10 \text { days })\end{array}$ & $\begin{array}{c}\text { Vitamin } \mathrm{D}_{3} \\
\text { (300 } \mu \mathrm{g} / \mathrm{kg} \text { body weight, administered } \\
\text { intramuscularly, once } 10 \text { days before } \\
\text { sacrifice) }\end{array}$ \\
\hline$V D R$ & $\begin{array}{l}1.398 \pm 0.198 \\
(1 \pm 0.092)\end{array}$ & $\begin{array}{l}1.014 \pm 0.204 \\
(1 \pm 0.184)\end{array}$ & $\begin{array}{c}1.000 \pm 0.190 \\
(1 \pm 0.198)\end{array}$ \\
\hline$P X R$ & $\begin{array}{c}0.666 \pm 0.096^{*} \\
(1 \pm 0.120)\end{array}$ & $\begin{array}{c}0.889 \pm 0.137 \\
(1 \pm 0.211)\end{array}$ & $\begin{array}{c}0.950 \pm 0.094 \\
(1 \pm 0.161)\end{array}$ \\
\hline СУРЗА9 & $\begin{array}{l}1.157 \pm 0.235 \\
(1 \pm 0.196)\end{array}$ & $\begin{array}{c}0.983 \pm 0.064 \\
(1 \pm 0.122)\end{array}$ & $\begin{array}{c}1.223 \pm 0.119 \\
(1 \pm 0.104)\end{array}$ \\
\hline CYP3A18 & $\begin{array}{l}0.661 \pm 0.094^{*} \\
(1 \pm 0.097)\end{array}$ & $\begin{array}{l}0.789 \pm 0.071 \\
(1 \pm 0.118)\end{array}$ & $\begin{array}{l}1.115 \pm 0.175 \\
(1 \pm 0.074)\end{array}$ \\
\hline CYP3A62 & $\begin{array}{c}1.087 \pm 0.183 \\
(1 \pm 0.084)\end{array}$ & $\begin{array}{l}0.875 \pm 0.089 \\
(1 \pm 0.135)\end{array}$ & $\begin{array}{c}1.166 \pm 0.119 \\
(1 \pm 0.062)\end{array}$ \\
\hline$M D R 1 a$ & $\begin{array}{c}0.828 \pm 0.099 \\
(1 \pm 0.139)\end{array}$ & $\begin{array}{c}0.946 \pm 0.107 \\
(1 \pm 0.102)\end{array}$ & $\begin{array}{c}1.218 \pm 0.149 \\
(1 \pm 0.158)\end{array}$ \\
\hline$M D R 1 b$ & $\begin{array}{c}1.398 \pm 0.254 \\
(1 \pm 0.222)\end{array}$ & $\begin{array}{c}0.813 \pm 0.097 \\
(1 \pm 0.230)\end{array}$ & $\begin{array}{c}1.437 \pm 0.256 \\
(1 \pm 0.152)\end{array}$ \\
\hline
\end{tabular}

Means \pm SEM of respective control groups set to 1 are given in brackets; asterisks indicate significant differences between treatment and control groups; ${ }^{*} P<0.05$.

TABLE 7: RNA expression in the brain of rats treated with different vitamin D metabolites normalized to GAPDH.

\begin{tabular}{|c|c|c|c|}
\hline & $\begin{array}{c}1,25-(\mathrm{OH})_{2} \mathrm{D}_{3} \\
(0.5 \mu \mathrm{g} / \mathrm{kg} \text { body weight, administered } \\
\text { intraperitoneally once, } 12 \mathrm{~h} \text { before } \\
\text { sacrifice })\end{array}$ & $\begin{array}{c}25-\mathrm{OHD}_{3} \\
(6 \mu \mathrm{g} / \mathrm{kg} \text { body weight, administered daily } \\
\text { by oral gavage for } 10 \text { days })\end{array}$ & $\begin{array}{c}\text { Vitamin } \mathrm{D}_{3} \\
\text { (300 } \mu \mathrm{g} / \mathrm{kg} \text { body weight, administered } \\
\text { intramuscularly, once } 10 \text { days before } \\
\text { sacrifice) }\end{array}$ \\
\hline$V D R$ & $\begin{array}{c}0.853 \pm 0.051 \\
(1 \pm 0.193)\end{array}$ & $\begin{array}{l}0.983 \pm 0.054 \\
(1 \pm 0.111)\end{array}$ & $\begin{array}{c}0.950 \pm 0.073 \\
(1 \pm 0.106)\end{array}$ \\
\hline$P X R$ & $\begin{array}{l}2.128 \pm 0.992^{\#} \\
(1 \pm 0.216)\end{array}$ & $\begin{array}{l}1.045 \pm 0.045 \\
(1 \pm 0.115)\end{array}$ & $\begin{array}{l}1.710 \pm 0.656 \\
(1 \pm 0.168)\end{array}$ \\
\hline$B C R P$ & $\begin{array}{c}0.703 \pm 0.072^{*} \\
\quad(1 \pm 0.071)\end{array}$ & $\begin{array}{c}1.145 \pm 0.107 \\
(1 \pm 0.125)\end{array}$ & $\begin{array}{c}1.371 \pm 0.183 \\
(1 \pm 0.095)\end{array}$ \\
\hline$M D R 1 a$ & $\begin{array}{l}0.719 \pm 0.052^{* *} \\
\quad(1 \pm 0.065)\end{array}$ & $\begin{array}{c}0.971 \pm 0.066 \\
(1 \pm 0.070)\end{array}$ & $\begin{array}{c}1.045 \pm 0.084 \\
(1 \pm 0.068)\end{array}$ \\
\hline$M D R 1 b$ & $\begin{array}{c}0.975 \pm 0.109 \\
(1 \pm 0.209)\end{array}$ & $\begin{array}{c}1.027 \pm 0.162 \\
(1 \pm 0.171)\end{array}$ & $\begin{array}{c}1.187 \pm 0.170 \\
(1 \pm 0.137)\end{array}$ \\
\hline
\end{tabular}

Means \pm SEM of respective control groups set to 1 are given in brackets; asterisks indicate significant differences between treatment and control groups; ${ }^{\#} P=0.053,{ }^{*} P<0.05$, and ${ }^{* *} P<0.01$. 


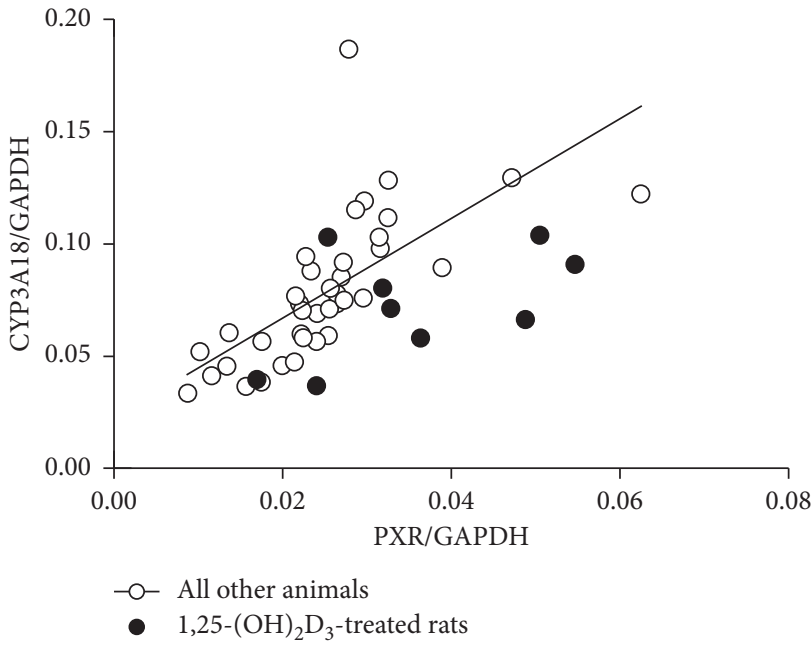

(a)

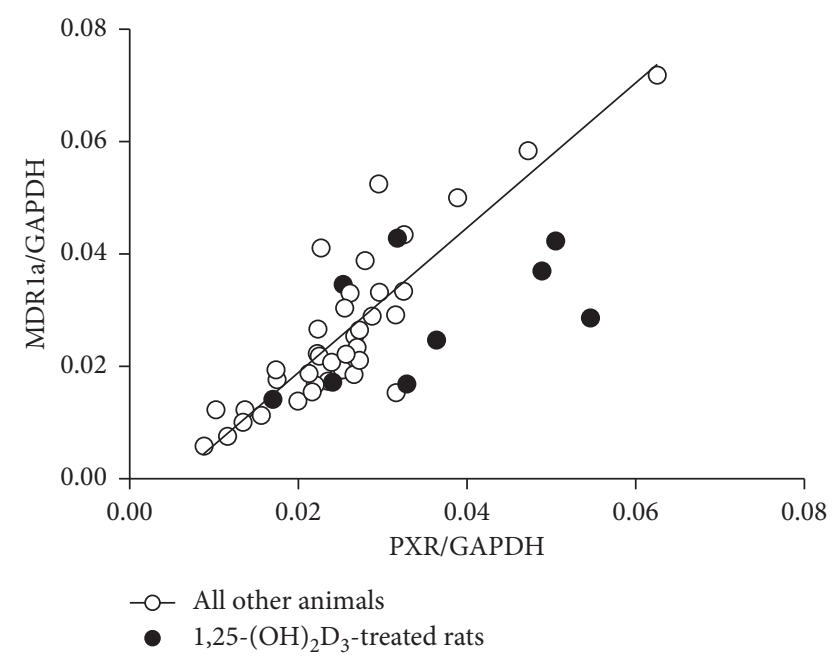

(b)

FIGURE 1: Regression analyses revealing linear correlations between the expression of PXR and CYP3A18 $(y=2.220 \pm 0.391 x-0.022 \pm 0.011$, $\left.r^{2}: 0.47, P<0.001\right)$ and MDR1a $\left(y=1.290 \pm 0.121 x-0.007 \pm 0.003, r^{2}: 0.75, P<0.001\right)$ in the proximal jejunum in all groups except for rats treated with $0.5 \mu \mathrm{g} / \mathrm{kg}$ body weight $12 \mathrm{~h}$ before sacrifice.

over time revealed a second-order polynomial model $\left(y=b 0+b 1 \cdot x+b 2 \cdot x^{2}\right.$, Figure 2) that differed between placebo and treatment groups for the animals that had received $25-\mathrm{OHD}_{3}$ (b0: $1.36 \pm 6.96$ and $1.04 \pm 8.85, b 1:-0.118 \pm 0.218$ and $-0.019 \pm 0.278, b 2: 0.0031 \pm 0.0014$ and $0.0041 \pm 0.0018$, $P<0.001)$ as well as for those treated with vitamin $\mathrm{D}_{3}(b 0$ : $0.78 \pm 4.89$ and $0.93 \pm 6.05, \quad b 1: \quad-0.056 \pm 0.153$ and $0.053 \pm 0.190, \quad b 2: \quad 0.0028 \pm 0.0010$ and $0.0036 \pm 0.0012$, $P<0.001)$. When compared with 2 -way ANOVA for repeated measures followed by Bonferroni's posttest, significant effects could be confirmed for the factors time $(P<0.001)$ and interaction of time and treatment $(P<0.05)$ for the $25-\mathrm{OHD}_{3}-$ group with significant differences between the concentrations determined after $150 \mathrm{~min}$ of incubation $(P<0.05)$. For animals treated with vitamin $\mathrm{D}_{3}$, significant effects could be confirmed for the factors time $(P<0.001)$, treatment $(P<0.05)$, and interaction of time and treatment $(P<0.01)$ with significant differences between the concentrations determined after $120 \mathrm{~min}(P<0.05)$ and $150 \mathrm{~min}$ of incubation $(P<0.01)$.

\section{Discussion}

Vitamin D responsive elements have been shown in the promotor regions of human MDR1 and CYP3A4 genes as well as in that of the rat CYP3A9 gene [21, 32, 33]. In contrast to some results previously obtained in rats and sheep treated with $1,25-(\mathrm{OH})_{2} \mathrm{D}_{3}[25,28]$, neither isoenzymes belonging to the CYP3A family investigated nor MDR1a/b was upregulated by intraperitoneal administration of $1,25-(\mathrm{OH})_{2} \mathrm{D}_{3}$ in the present study. It should be noted that, in most previous studies with rodents, $1,25-(\mathrm{OH})_{2} \mathrm{D}_{3}$ was administered repeatedly or at higher doses. Our serum analysis data and that of RNA expression of genes involved in vitamin $\mathrm{D}$ metabolism and calcium transport indicate clearly that the vitamin $\mathrm{D}$ metabolites were administered correctly and absorbed efficiently. However, from the results on CYP24A1 and CYP27B1 expression, it might be concluded that rats are generally less sensitive to $25-\mathrm{OHD}_{3}$ than sheep [25].

In addition, the different response in comparison to sheep could be explained by species-dependent induction of CYP3A enzymes. The predominant regulator of CYP3A enzymes is PXR [34]. The human PXR has been shown to bind hydroxylated vitamin D metabolites [35]. In contrast to other members of the nuclear receptor family, a comparison of the PXR sequences from different mammalian species showed that the proteins share less than $80 \%$ amino acid identity in their ligand binding domain (LBD) [36]. The striking differences in the LBD are assumed to be responsible for the selectivity in ligand binding and thus for the differences observed in respect to the induction profiles. For example, rifampicin, but not dexamethasone, induces CYP3A expression in human liver cells, while rat liver cells respond to dexamethasone but not to rifampicin [37]. As differences in the activity of enzymatic biotransformation could be found even between sheep and goats [38] or when different cattle breeds were compared [39], results on pharmacokinetics cannot be easily extrapolated from one species or breed to another.

The observation that none of the intestinal CYP3A enzymes investigated was upregulated with the $1,25-(\mathrm{OH})_{2} \mathrm{D}_{3}$ treatment is in line with results from $\mathrm{Xu}$ et al., who found a selective induction of CYP3A1/23, the isoform that was not addressed here [23]. However, interestingly, hepatic CYP3A18 as well as intestinal CYP3A9 RNA expression were both downregulated in the present study. This contrasts with a report of Khan et al. [40], where no effect of $1,25-(\mathrm{OH})_{2} \mathrm{D}_{3}$ on rat intestinal and hepatic CYP3A9 could be found, although the same treatment induced an upregulation of CYP3A4 in human tissues. In the present study, a reduction in PXR expression could be shown in the liver and the kidney with 


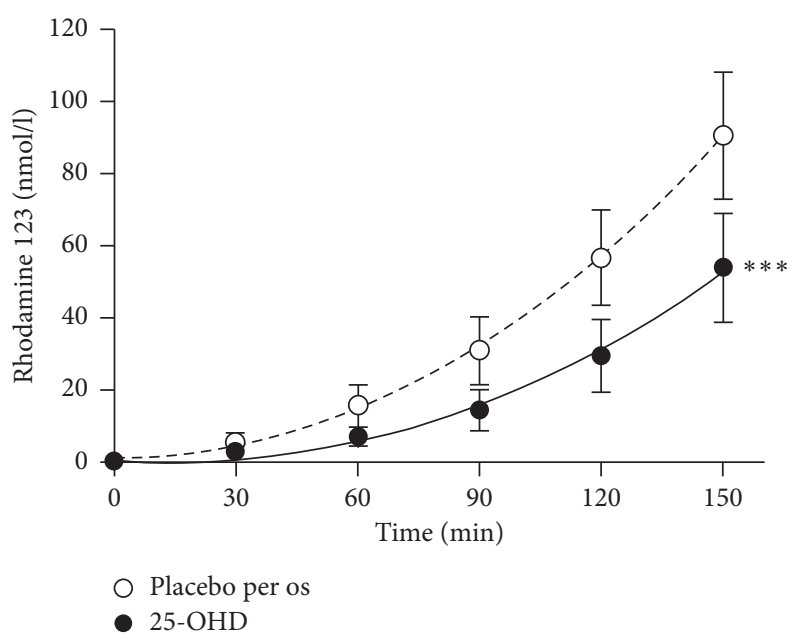

(a)

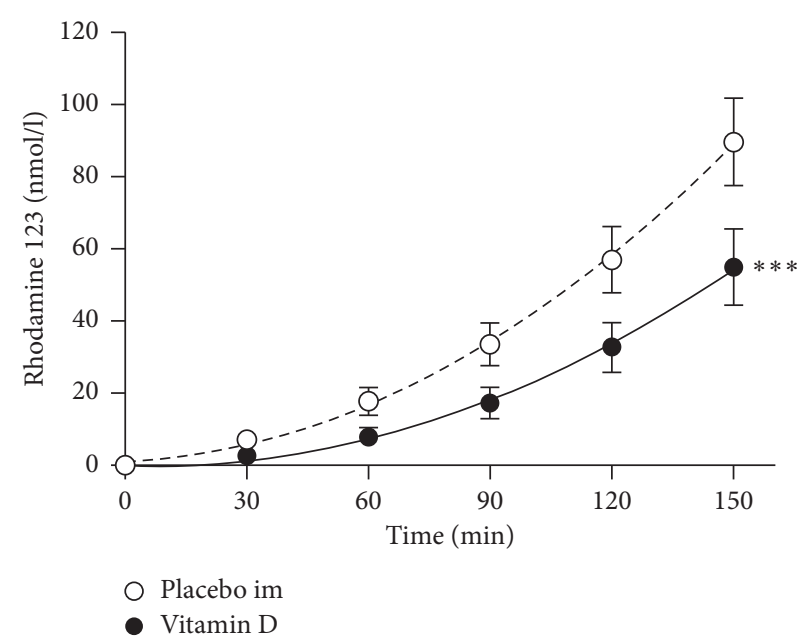

(b)

FIGURE 2: Net increase in the mucosal concentration of rhodamine-123 (minus increase in serosal concentration) after inhibition of rhodamine-123 transport by addition of verapamil to the mucosal compartment. Given are results obtained with ileal preparations of rats treated with $6 \mu \mathrm{g} 25$-hydroxyvitamin D3 $\left(25-\mathrm{OHD}_{3}\right)$ per kg BW per os daily for 10 days or $300 \mu \mathrm{g}$ vitamin $\mathrm{D}_{3}$ per kg BW intramuscularly once 10 days before sacrifice.

$1,25-(\mathrm{OH})_{2} \mathrm{D}_{3}$-treatment and also in the kidney with vitamin $\mathrm{D}_{3}$-treatment, but the same $1,25-(\mathrm{OH})_{2} \mathrm{D}_{3}$-protocol stimulated renal PXR expression in sheep [25]. Although other important nuclear receptors like the constitutive androstane receptor and the liver X receptor were not included in this study, these results further underline the relevance of species-specific mechanisms of CYP3A induction. At least for the liver, the response of CYP3A18 expression observed in our rats might be mediated by the decreased expression of PXR that could affect the activation by endogenous ligands [40]. PXR expression has been shown to correlate with CYP3A expression in humans [41]. In the present study, such a correlation with PXR could only be found for the expression of CYP3A18 and MDR1a in the proximal jejunum. Interestingly, no linear relationship could be revealed for rats treated with $1,25-(\mathrm{OH})_{2} \mathrm{D}_{3}$ (Figure 1). This observation might indicate an interference of the treatment with regulatory pathways involving PXR.

The effect of the treatment with $25-\mathrm{OHD}_{3}$ and vitamin $\mathrm{D}_{3}$ on intestinal activity of $\mathrm{P}$-gp only became apparent after inhibition of P-gp with verapamil. In both treated groups, the inhibition seemed to last longer than in the respective control groups (Figure 2). The use of rhodamine-123 as a $\mathrm{P}$-gp-substrate and verapamil as a $\mathrm{P}$-gp-inhibitor is well established [42-44]. However, a significant efflux of rhodamine-123 mediated by other transport proteins, such as multidrug-related-proteins (MRPs), has to be considered $[45,46]$. In the present study, the contribution of other transporters to the net increase of rhodamine-123 in the mucosal compartment has not been investigated. Besides a variation in the abundance of efflux transporters in the animals treated with vitamin $\mathrm{D}$ metabolites, alterations in the expression pattern or activity of CYP3A enzymes might explain the different responses to the inhibition of P-gp. Verapamil itself is metabolized by intestinal CYP3A enzymes [47]. Although we could not find any alterations in the RNA expression of the CYP3A isoenzymes investigated, it might be speculated that administration of $25-\mathrm{OHD}_{3}$ and vitamin $D_{3}$ led to a change in the relative activity of the different isoforms of CYP3A enzymes resulting in a slower metabolism of the applied inhibitor.

On the other hand, the observed effect might be a direct effect of vitamin D metabolites on P-gp function. Inhibition of P-gp cannot only occur by influencing its expression but also by alteration of the ATPase activity or competition for binding sites. Although verapamil competes with other substrates for the P-gp binding sites, it also increases its ATPase activity [48]. Progesterone and desoxycorticosterone diminish this stimulating effect of verapamil in a dosedependent manner [49]. Recently, it could be demonstrated that $25-\mathrm{OHD}_{3}$ and vitamin $\mathrm{D}_{3}$ decrease the verapamil-induced ATPase activity of P-gp in membranes of Sf9 insect cells overexpressing human P-gp too, while under basal conditions, only vitamin $\mathrm{D}_{3}$ exerted a slight effect [8]. This is in line with our observation that significant effects could be found for rhodamine-123 transport only after addition of verapamil.

In brain tissues, we investigated P-gp and BCRP because these transporters share a broad range of substrates and BCRP is upregulated in the blood-brain barrier of MDR1a k.o. mice $[50,51]$. In contrast to Durk et al. [52], we did not find an upregulation but rather a significant downregulation of MDR1a and BCRP with the 1,25- $(\mathrm{OH})_{2} \mathrm{D}_{3}$ treatment. Given that our treatment induced expression and activity of CYP24A1, it can be assumed that as a side-effect there was an increase in vitamin D metabolites hydroxylated at carbon 24 . In fish and chickens, $24,25-(\mathrm{OH})_{2} \mathrm{D}_{3}$ has been demonstrated to exert opposite effects to $1,25-(\mathrm{OH})_{2} \mathrm{D}_{3}$, e.g., a decrease in calcium absorption $[53,54]$. Whether such negative impacts of vitamin metabolites hydroxylated at carbon 24 could also play a role in the regulation of nonclassical vitamin $\mathrm{D}$ responsive genes has not yet been investigated. But if there were such an effect, it could probably be overcome by the 
much higher and/or repeatedly administered dosage of 1,25$(\mathrm{OH})_{2} \mathrm{D}_{3}$ in these reported studies. Another explanation could be an interaction between VDR, PXR, and the estrogen receptor or respective estrogen responsive elements in certain promoters. BCRP is downregulated in brain tissues by $17 \beta$-estradiol [55]. At least in breast cancer cells, 1,25$(\mathrm{OH})_{2} \mathrm{D}_{3}$ interacts with estrogen-responsive elements [56]. In addition, metabolic pathways induced by the upregulation of PXR could affect the tissue concentration of estrogens $[57,58]$.

In summary, our results show that the stimulating effects of vitamin D metabolites on the expression of genes involved in the metabolism and elimination of xenobiotics previously reported for rats and cell culture systems and, in case of CYP3A also in sheep, could not be reproduced using the treatment protocol applied here. However, alterations of P-gp activity as well as an impact on the expression of some CYP3A isoenzymes and the transcription factor PXR cannot be excluded.

\section{Data Availability}

The data used to support this study are included within the article.

\section{Conflicts of Interest}

The authors have declared no conflicts of interest.

\section{Acknowledgments}

This research was partly supported by the $\mathrm{H}$. Wilhelm Schaumann Foundation. This publication was supported by the Deutsche Forschungsgemeinschaft and University of Veterinary Medicine Hannover, Foundation within the funding programme Open Access Publishing.

\section{References}

[1] J. Gahche, R. Bailey, V. Burt et al., "Dietary supplement use among U.S. adults has increased since NHANES III (19881994)," NCHS Data Brief, vol. 61, pp. 1-8, 2011.

[2] K. Bilinski and P. Talbot, "Vitamin D supplementation in Australia: implications for the development of supplementation guidelines," Journal of Nutrition and Metabolism, vol. 2014, Article ID 374208, 4 pages, 2014.

[3] O. M. Radostits, J. H. Arundel, C. C. Gay, and D. C. Blood, Veterinary Medicine: A Textbook of the Diseases of Cattle, Sheep, Pigs, Goats and Horses, Saunders, Philadelphia, PA, USA, 2000.

[4] M. R. Wilkens, I. Oberheide, B. Schröder, E. Azem, W. Steinberg, and G. Breves, "Influence of the combination of 25-hydroxy vitamin D3 and a diet negative in cation-anion difference on peripartal calcium homeostasis of dairy cows," Journal of Dairy Science, vol. 95, no. 1, pp. 151-164, 2012.

[5] W. P. Weiss, E. Azem, W. Steinberg, and T. A. Reinhardt, "Effect of feeding 25-hydroxy vitamin D3 with a negative cation-anion difference diet on calcium and vitamin D status of periparturient cows and their calves," Journal of Dairy Science, vol. 98, no. 8, pp. 5588-5600, 2015.
[6] J. H. Lin and A. Y. H. Lu, "Inhibition and induction of cytochrome P450 and the clinical implications," Clinical Pharmacokinetics, vol. 35, no. 5, pp. 361-390, 1998.

[7] M. Lund, T. S. Petersen, and K. P. Dalhoff, "Clinical implications of P-glycoprotein modulation in drug-drug interactions," Drugs, vol. 77, no. 8, pp. 859-883, 2017.

[8] M. Margier, X. Collet, C. le May et al., "ABCB1 (P-glycoprotein) regulates vitamin $\mathrm{D}$ absorption and contributes to its transintestinal efflux," The FASEB Journal, vol. 33, no. 2, pp. 2084-2094, 2019.

[9] Z. Wang, Y. S. Lin, X. E. Zheng et al., "An inducible cytochrome P450 3A4-dependent vitamin D catabolic pathway," Molecular Pharmacology, vol. 81, no. 4, pp. 498-509, 2012.

[10] J. D. Lindh, M. L. Andersson, E. Eliasson, and L. BjörkhemBergman, "Seasonal variation in blood drug concentrations and a potential relationship to vitamin D," Drug Metabolism and Disposition, vol. 39, no. 5, pp. 933-937, 2011.

[11] T. Sakaeda, T. Nakamura, and K. Okumura, "Pharmacogenetics of MDR1 and its impact on the pharmacokinetics and pharmacodynamics of drugs," Pharmacogenomics, vol. 4, no. 4, pp. 397-410, 2003.

[12] J. Schwartz, "Effects of vitamin D supplementation in atorvastatin-treated patients: a new drug interaction with an unexpected consequence," Clinical Pharmacology \& Therapeutics, vol. 85, no. 2, pp. 198-203, 2009.

[13] B. P. Kota, M. I. M. Abdul, J. D. Allen, M. Kalagara, and B. D. Roufogalis, "Effect of vitamin D3 supplementation on the pharmacokinetics of digoxin-a pilot study," Fundamental \& Clinical Pharmacology, vol. 26, no. 4, pp. 543-548, 2012.

[14] P. Schmiedlin-Ren, K. E. Thummel, J. M. Fisher, M. F. Paine, K. S. Lown, and P. B. Watkins, "Expression of enzymatically active CYP3A4 by caco-2 cells grown on extracellular matrixcoated permeable supports in the presence of $1 \alpha, 25$-dihydroxy vitamin D3," Molecular Pharmacology, vol. 51, no. 5, pp. 741-754, 1997.

[15] P. Schmiedlin-Ren, K. E. Thummel, J. M. Fisher, M. F. Paine, and P. B. Watkins, "Induction of CYP3A4 by 1 alpha,25dihydroxy vitamin D3 is human cell line-specific and is unlikely to involve pregnane X receptor," Drug Metabolism and Disposition: The Biological Fate of Chemicals, vol. 29, pp. 1446-1453, 2001.

[16] L. Drocourt, J.-C. Ourlin, J.-M. Pascussi, P. Maurel, and M.-J. Vilarem, "Expression of CYP3A4, CYP2B6, and CYP2C9 is regulated by the vitamin D receptor pathway in primary human hepatocytes," Journal of Biological Chemistry, vol. 277, no. 28, pp. 25125-25132, 2002.

[17] J. Fan, S. Liu, Y. Du, J. Morrison, R. Shipman, and K. S. Pang, "Up-regulation of transporters and enzymes by the vitamin D receptor ligands, $1 \alpha, 25$-dihydroxy vitamin D3 and vitamin D analogs, in the caco-2 cell monolayer," Journal of Pharmacology and Experimental Therapeutics, vol. 330, no. 2, pp. 389-402, 2009.

[18] K. Takara, N. Ohnishi, S. Horibe, and T. Yokoyama, "Expression profiles of drug-metabolizing enzyme CYP3A and drug efflux transporter multidrug resistance 1 subfamily mRNAs in rat small intestine," Drug Metabolism and Disposition, vol. 31, no. 10, pp. 1235-1239, 2003.

[19] H.-C. Shin, H.-R. Kim, H.-J. Cho et al., "Comparative gene expression of intestinal metabolizing enzymes," Biopharmaceutics \& Drug Disposition, vol. 30, no. 8, pp. 411-421, 2009.

[20] T. Matsubara, H. J. Kim, M. Miyata, M. Shimada, K. Nagata, and Y. Yamazoe, "Isolation and characterization of a new 
major intestinal CYP3A form, CYP3A62, in the rat," Journal of Pharmacology and Experimental Therapeutics, vol. 309, no. 3, pp. 1282-1290, 2004.

[21] C. Zierold, J. A. Mings, and H. F. Deluca, "19nor-1,25Dihydroxy vitamin D2 specifically induces CYP3A9 in rat intestine more strongly than 1,25-dihydroxy vitamin D3 in vivo and in vitro," Molecular Pharmacology, vol. 69, no. 5, pp. 1740-1747, 2006.

[22] E. C. Y. Chow, H.-J. Maeng, S. Liu, A. A. Khan, G. M. M. Groothuis, and K. S. Pang, " $1 \alpha, 25$-dihydroxy vitamin D3 triggered vitamin D receptor and farnesoid X receptor-like effects in rat intestine and liverin vivo," Biopharmaceutics \& Drug Disposition, vol. 30, no. 8, pp. 457-475, 2009.

[23] Y. Xu, K. Iwanaga, C. Zhou, M. J. Cheesman, F. Farin, and K. E. Thummel, "Selective induction of intestinal CYP3A23 by $1 \alpha, 25$-dihydroxy vitamin D3 in rats," Biochemical Pharmacology, vol. 72, no. 3, pp. 385-392, 2006.

[24] E. C. Chow, H. Sun, A. A. Khan, G. M. Groothuis, and K. S. Pang, "Effects of 1alpha,25-dihydroxy vitamin D3 on transporters and enzymes of the rat intestine and kidney in vivo," Biopharmaceutics \& Drug Disposition, vol. 31, pp. 91108, 2010.

[25] M. R. Wilkens, L. M. Maté, N. Schnepel et al., "Influence of 25hydroxy vitamin D3 and 1,25-dihydroxy vitamin D3 on expression of P-glycoprotein and cytochrome P450 3A in sheep," The Journal of Steroid Biochemistry and Molecular Biology, vol. 164, pp. 271-276, 2016.

[26] L. Stuchlíková, P. Matoušková, H. Bártíková et al., "Monepantel induces hepatic cytochromes 450 in sheep in vitro and in vivo," Chemico-Biological Interactions, vol. 227, pp. 63-68, 2015.

[27] H.-J. Maeng, M. R. Durk, E. C. Y. Chow, R. Ghoneim, and K. S. Pang, " $1 \alpha, 25$-Dihydroxy vitamin D3 on intestinal transporter function: studies with the rat everted intestinal sac," Biopharmaceutics \& Drug Disposition, vol. 32, no. 2, pp. 112-125, 2011.

[28] E. C. Y. Chow, M. R. Durk, C. L. Cummins, and K. S. Pang, "1 $\alpha, 25$-Dihydroxy vitamin D3 up-regulates P-glycoprotein via the vitamin $\mathrm{D}$ receptor and not farnesoid $\mathrm{X}$ receptor in both $\mathrm{fxr}(-/-)$ and $\mathrm{fxr}(+/+)$ mice and increased renal and brain efflux of digoxin in mice in vivo," Journal of Pharmacology and Experimental Therapeutics, vol. 337, no. 3, pp. 846-859, 2011.

[29] B. C. Sarkar and U. P. Chauhan, "A new method for determining micro quantities of calcium in biological materials," Analytical Biochemistry, vol. 20, no. 1, pp. 155-166, 1967.

[30] A. Peinnequin, C. Mouret, O. Birot et al., "Rat pro-inflammatory cytokine and cytokine related mRNA quantification by real-time polymerase chain reaction using SYBR green," BMC Immunology, vol. 5, no. 1, p. 3, 2004.

[31] M. R. Wilkens, C. Kunert-Keil, H. Brinkmeier, and B. Schröder, "Expression of calcium channel TRPV6 in ovine epithelial tissue," The Veterinary Journal, vol. 182, no. 2, pp. 294-300, 2009.

[32] P. D. Thompson, P. W. Jurutka, G. Kerr Whitfield et al., "Liganded VDR induces CYP3A4 in small intestinal and colon cancer cells via DR3 and ER6 vitamin D responsive elements," Biochemical and Biophysical Research Communications, vol. 299, no. 5, pp. 730-738, 2002.

[33] M. Saeki, K. Kurose, M. Tohkin, and R. Hasegawa, "Identification of the functional vitamin D response elements in the human MDR1 gene," Biochemical Pharmacology, vol. 76, no. 4, pp. 531-542, 2008.
[34] C. Xu, C. Y.-T. Li, and A.-N. T. Kong, "Induction of phase I, II and III drug metabolism/transport by xenobiotics," Archives of Pharmacal Research, vol. 28, no. 3, pp. 249-268, 2005.

[35] M. N. Jacobs, G. T. Nolan, and S. R. Hood, "Lignans, bacteriocides and organochlorine compounds activate the human pregnane X receptor (PXR)," Toxicology and Applied Pharmacology, vol. 209, no. 2, pp. 123-133, 2005.

[36] S. A. Jones, L. B. Moore, J. L. Shenk et al., "The pregnane X receptor: a promiscuous xenobiotic receptor that has diverged during evolution," Molecular Endocrinology, vol. 14, no. 1, pp. 27-39, 2000.

[37] C. Lu and A. P. Li, "Species comparison in P450 induction: effects of dexamethasone, omeprazole, and rifampin on P450 isoforms $1 \mathrm{~A}$ and $3 \mathrm{~A}$ in primary cultured hepatocytes from man, Sprague-Dawley rat, minipig, and beagle dog," Chemicobiological Interactions, vol. 134, no. 3, pp. 271-281, 2001.

[38] B. Szotakova, V. Baliharová, J. Lamka et al., "Comparison of in vitro activities of biotransformation enzymes in pig, cattle, goat and sheep," Research in Veterinary Science, vol. 76, no. 1, pp. 43-51, 2004.

[39] M. Dacasto, C. Eeckhoutte, F. Capolongoa et al., "Effect of breed and gender on bovine liver cytochrome P450 3A (CYP3A) expression and inter-species comparison with other domestic ruminants," Veterinary Research, vol. 36, no. 2, pp. 179-190, 2005.

[40] A. A. Khan, E. C. Y. Chow, A.-M. M. A. van Loenen-Weemaes, R. J. Porte, K. S. Pang, and G. M. M. Groothuis, "Comparison of effects of VDR versus PXR, FXR and GR ligands on the regulation of CYP3A isozymes in rat and human intestine and liver," European Journal of Pharmaceutical Sciences, vol. 37, no. 2, pp. 115-125, 2009.

[41] A. Westlind-Johnsson, S. Malmebo, A. Johansson et al., "Comparative analysis of CYP3A expression in human liver suggests only a minor role for CYP3A5 in drug metabolism," Drug Metabolism and Disposition, vol. 31, no. 6, pp. 755-761, 2003.

[42] M. Ballent, M. R. Wilkens, L. Maté et al., "P-glycoprotein in sheep liver and small intestine: gene expression and transport efflux activity," Journal of Veterinary Pharmacology and Therapeutics, vol. 36, no. 6, pp. 576-582, 2013.

[43] A. Fortuna, G. Alves, A. Falcão, and P. Soares-da-Silva, "Evaluation of the permeability and P-glycoprotein efflux of carbamazepine and several derivatives across mouse small intestine by the Using chamber technique," Epilepsia, vol. 53, no. 3, pp. 529-538, 2012.

[44] J. Iqbal, J. Hombach, B. Matuszczak, and A. BernkopSchnürch, "Design and in vitro evaluation of a novel polymeric P-glycoprotein (P-gp) inhibitor," Journal of Controlled Release, vol. 147, no. 1, pp. 62-69, 2010.

[45] P. R. Twentyman, T. Rhodes, and S. Rayner, "A comparison of rhodamine 123 accumulation and efflux in cells with P-glycoprotein-mediated and MRP-associated multidrug resistance phenotypes," European Journal of Cancer, vol. 30, no. 9, pp. 1360-1369, 1994.

[46] J. Pétriz, J. E. O’Connor, M. Carmona, and J. García-López, “Is rhodamine 123 an appropriate fluorescent probe to assess P-glycoprotein mediated multidrug resistance in vinblastineresistant CHO cells?," Analytical Cellular Pathology, vol. 14, no. 3, pp. 129-140, 1997.

[47] H. K. Kroemer, J. C. Gautier, P. Beaune, C. Henderson, C. R. Wolf, and M. Eichelbaum, "Identification of P450 enzymes involved in metabolism of verapamil in humans," Naunyn-Schmiedeberg's Archives of Pharmacology, vol. 348, no. 3, pp. 332-337, 1993. 
[48] S. Dewanjee, T. K. Dua, N. Bhattacharjee et al., "Natural products as alternative choices for P-glycoprotein (P-gp) inhibition," Molecules, vol. 22, no. 6, p. 871, 2017.

[49] S. Orlowski, L. M. Mir, J. Belehradek Jr., and M. Garrigos, "Effects of steroids and verapamil on P-glycoprotein ATPase activity: progesterone, desoxycorticosterone, corticosterone and verapamil are mutually non-exclusive modulators," Biochemical Journal, vol. 317, no. 2, pp. 515-522, 1996.

[50] S. Cisternino, C. Mercier, F. Bourasset, F. Roux, and J.-M. Scherrmann, "Expression, up-regulation, and transport activity of the multidrug-resistance protein $\mathrm{Abcg} 2$ at the mouse blood-brain barrier," Cancer Research, vol. 64, no. 9, pp. 3296-3301, 2004.

[51] W. Löscher and H. Potschka, "Blood-brain barrier active efflux transporters: ATP-binding cassette gene family," Neurotherapeutics, vol. 2, no. 1, pp. 86-98, 2005.

[52] M. R. Durk, J. Fan, H. Sun et al., "Vitamin D receptor activation induces P-glycoprotein and increases brain efflux of quinidine:an intracerebral microdialysis study in conscious rats," Pharmaceutical Research, vol. 32, no. 3, pp. 1128-1140, 2015.

[53] I. Nemere, "24,25-Dihydroxy vitamin D3 suppresses the rapid actions of 1,25-dihydroxy vitamin D3 and parathyroid hormone on calcium transport in chick intestine," Journal of Bone and Mineral Research, vol. 14, no. 9, pp. 1543-1549, 1999.

[54] D. Larsson, B. T. Björnsson, and K. Sundell, "Physiological concentrations of 24,25-dihydroxy vitamin D3 rapidly decrease the in vitro intestinal calcium uptake in the Atlantic cod, Gadus morhua," General and Comparative Endocrinology, vol. 100, no. 2, pp. 211-217, 1995.

[55] A. Mahringer and G. Fricker, "BCRP at the blood-brain barrier: genomic regulation by $17 \beta$-estradiol," Molecular Pharmaceutics, vol. 7, no. 5, pp. 1835-1847, 2010.

[56] E. Demirpence, P. Balaguer, F. Trousse, J. C. Nicolas, M. Pons, and D. Gagne, "Antiestrogenic effects of all-trans-retinoic acid and 1,25-dihydroxy vitamin D3 in breast cancer cells occur at the estrogen response element level but through different molecular mechanisms," Cancer Research, vol. 54, no. 6, pp. 1458-1464, 1994.

[57] J. Wang, S. Dai, Y. Guo, W. Xie, and Y. Zhai, "Biology of PXR: role in drug-hormone interactions," EXCLI Journal, vol. 13, pp. 728-739, 2014.

[58] A. F. Badawi, E. L. Cavalieri, and E. G. Rogan, "Role of human cytochrome P450 1A1, 1A2, 1B1, and 3A4 in the 2-, 4-, and 16 [alpha]-hydroxylation of 17[beta]-estradiol," Metabolism, vol. 50, no. 9, pp. 1001-1003, 2001. 


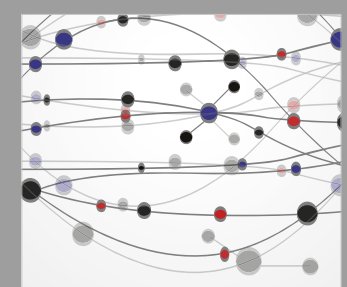

The Scientific World Journal
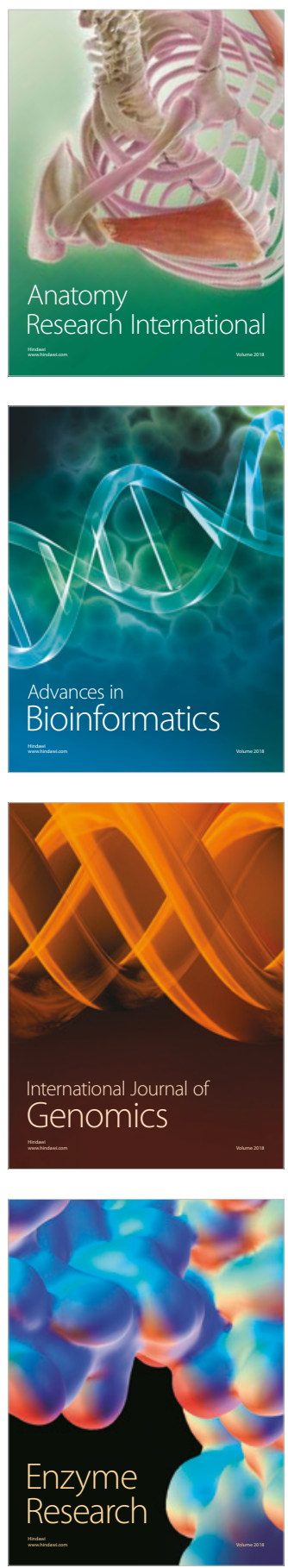
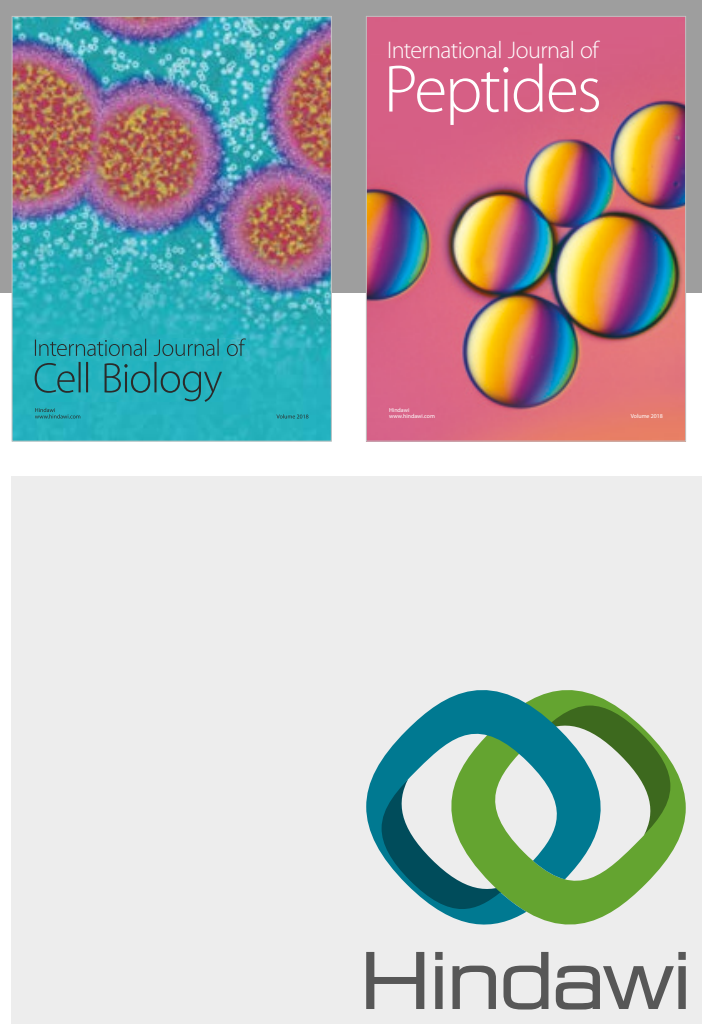

Submit your manuscripts at

www.hindawi.com
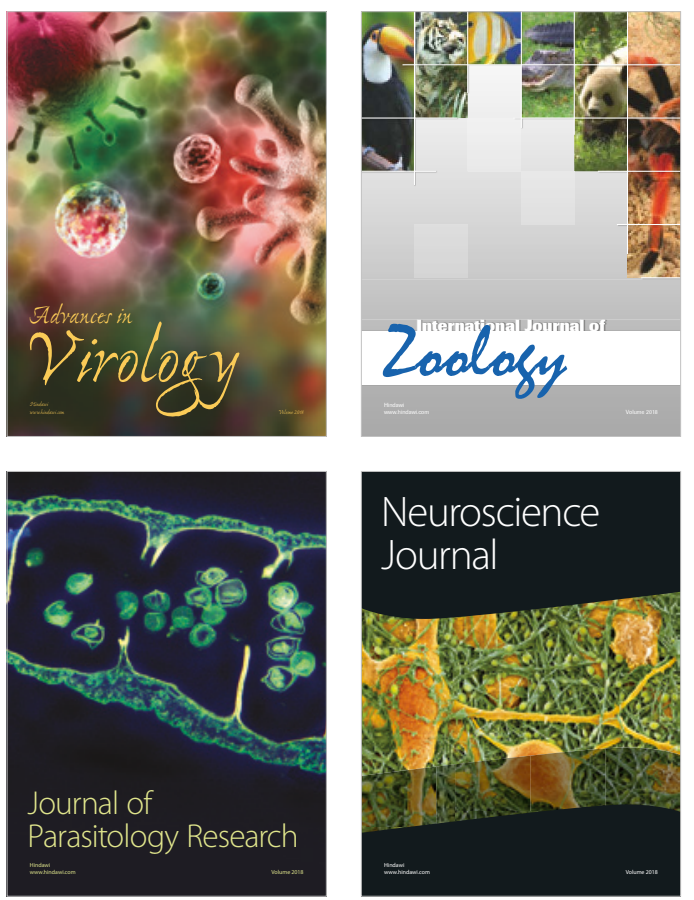
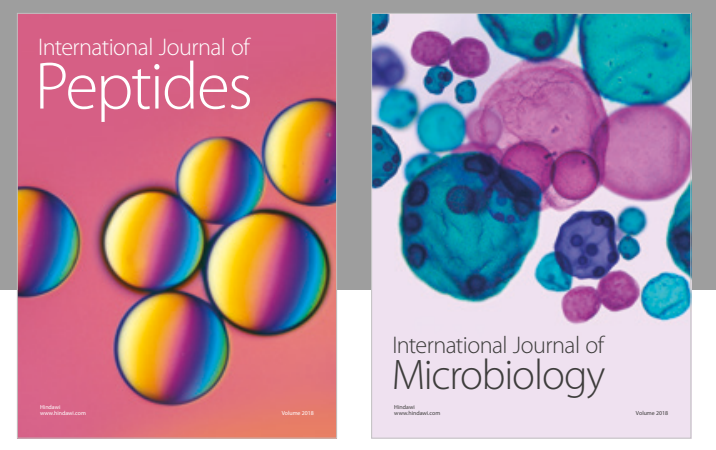

nternational Journal of Microbiology
Journal of
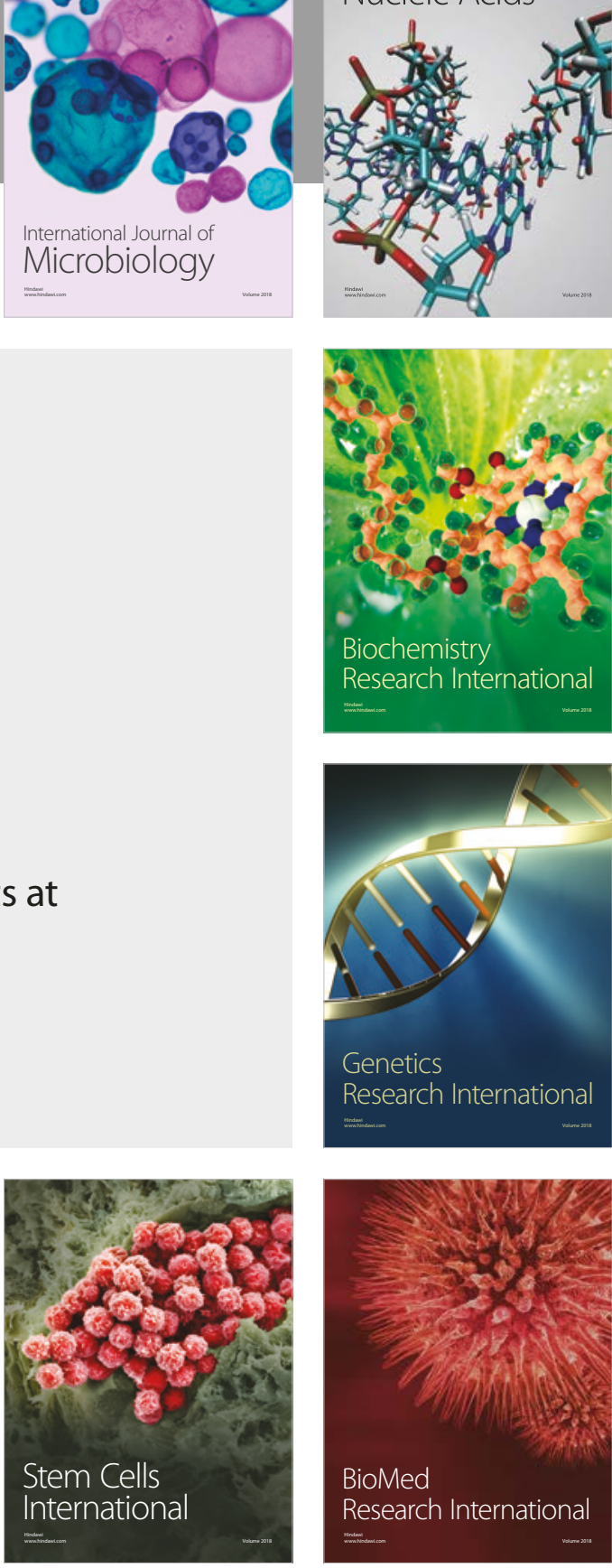
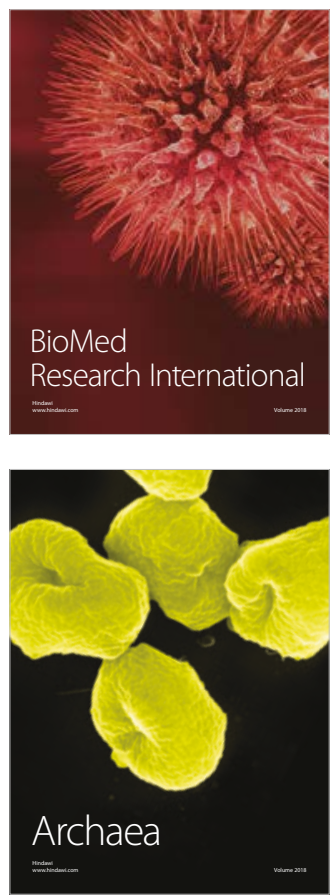